\title{
Organ Function Tests and Their Predictive Value in the Novel Coronavirus Disease 2019 Infection: A Retrospective Report from India
}

\author{
Megha Bangar, Supriya Khillare, Anita Chalak, Shalini Maksane* \\ Department of Biochemistry, Seth G.S. Medical College and K.E.M Hospital, Parel, Mumbai, India
}

*Correspondence to

Shalini Maksane,

Tel: 099-9113007168

Email: shalinidabi24@gmail.com

Received August 24, 2020

Accepted Septemeber 7, 2020

Published online Septemeber 30, 2020

\begin{abstract}
Introduction: Novel coronavirus disease 2019 (COVID-19) has become a global public health calamity since its outbreak in Wuhan, China in December 2019, and there is a lack of diagnostic biochemical data related to the disease. This study aimed to investigate routine biochemical parameters in COVID-19 positive Indian patients and check their predictive value for the detection of this novel disease.

Materials and Methods: This observational study was conducted retrospectively with the participation of 166 patients referred to King Edward Memorial (KEM) Hospital, Mumbai, India during May 2020. The baseline characteristics (age and gender) and biochemical data of individuals with COVID-19-related symptoms but negative for COVID-19 were collected and classified into two groups of real-time reverse transcriptase polymerase chain reaction (RT-PCR) and COVID-19 positive. The value of organ function tests (blood urea nitrogen [BUN], creatinine, and levels of serum electrolytes, alanine aminotransferase [ALT], aspartate aminotransferase (AST), bilirubin total, bilirubin direct, total protein, and albumin) were noted and analyzed. The groups were compared using unpaired t test, and predictive value of these parameters for COVID-19 was evaluated by calculating the area under the ROC curve (AUC).

Results: There was a significant rise in the serum AST ALT, bilirubin direct, BUN, and creatinine levels of COVID-19 subjects compared to non-COVID-19 ones $(\mathrm{P}<0.001)$. AST (AUC $=0.826$, $\mathrm{Cl}: 0.76$ to $0.89, \mathrm{P}<0.001$ ), ALT (AUC $=0.8525,95 \% \mathrm{Cl}: 0.79$ to $0.90, \mathrm{P}<0.001$ ), and $\mathrm{BUN}$ ( $\mathrm{AUC}=0.8097,95 \% \mathrm{Cl}: 0.74$ to $0.87, \mathrm{P}<0.001$ ) showed very good accuracy and serum creatinine $(A \cup C=0.7971,95 \% \mathrm{Cl}: 0.73$ to $0.86, \mathrm{P}<0.001)$ showed good accuracy in predicting COVID- 19 positivity.

Conclusion: Serum levels of ALT, AST, BUN, and creatinine can be the reliable predictors of COVID-19 test and identify infected patients.
\end{abstract}

Keywords: COVID-19, Liver function test, Kidney function test, Biochemical parameters
Please cite this article as follows: Bangar M, Khillare S, Chalak A, Maksane S. Organ Function Tests and Their Predictive Value in the Novel Coronavirus Disease 2019 Infection: A Retrospective Report from India . Int J Basic Sci Med. 2020;5(3):85 89. doi: $10.34172 /$ ijbms.2020.15.

\section{Introduction}

Novel coronavirus disease 2019 (COVID-19) is a transmittable disease caused by a newly discovered coronavirus. The outbreak initiated in Wuhan, China in December 2019. COVID-19 is currently a pandemic affecting nearly all countries of the world. ${ }^{1}$ The first case of the pandemic in India was reported on 30 January 2020. As of 8 June 2020, the Ministry of Health and Family Welfare has confirmed a total of 2057000 cases in India. ${ }^{2}$

Coronavirus is found in Alpha, Beta, Delta, and Gamma forms; these viruses can cause respiratory, hepatic, and neurological disorders in different animal species including humans. The novel coronavirus identified as severe acute respiratory syndrome (SARS-CoV) or COVID-19 virus belongs to Beta coronaviruses. ${ }^{3}$ As the disease is new to the world, the exact pathophysiological behaviour of the virus is not well-known yet. Karla et al states that to fight against this global pandemic, drastic research is needed for understanding the virus structure and the pathophysiology of this disease. ${ }^{3}$ Xiang et al observed that $20 \%$ of COVID-19 patients had severe

(C) 2020 The Author(s); Published by Zabol University of Medical Sciences. This is an open-access article distributed under the terms of the Creative Commons Attribution License (http://creativecommons.org/licenses/by/4.0), which permits unrestricted use, distribution, and reproduction in any medium, provided the original work is properly cited. 
symptoms with a mortality rate of $20 \%$. The mortality in severe patients has been found to be accompanied with the heart, liver, and kidney failure. ${ }^{4}$ Karla et $\mathrm{al}^{3}$ suggested that performing biochemical tests to assess the functions of liver and kidney along with electrolytes and coagulation profile might give indication for multiple organ dysfunction syndrome (MODS). Therefore, investigating the clinical and biochemical parameters can provide early, simple, and effective diagnosis of severe COVID-19 and play a significant role in reducing mortality and shortening the hospitalization period. ${ }^{5}$

Hence, there is an urgent need for recognition of laboratory predictors of the disease and its severity. Studying basic biochemical parameters might help not only to diagnose but also to predict MODS, develop new treatment strategies, and monitor drug responses.

Currently, there is a scarcity of data on the laboratory characteristics of COVID-19 patients, and we could find only few Indian studies on biochemical parameters in COVID-19 positive patients. Accordingly, the present study was designed to assess organ function tests which are routinely used for clinical and biochemical assessment of COVID-19 positive Indian patients and to check their predictive value for detecting this novel disease.

The findings of the study might also help to compare the biochemical behaviour of the disease in India and other parts of the world. As a result, it may help to understand the impact of altered environmental conditions and ethnicity on pathophysiological behaviour of COVID-19.

\section{Materials and Methods \\ Study Design and Setting}

This observational study was conducted in the Biochemistry Department of Seth Gordhandas Sunderdas Medical College and King Edward Memorial (KEM) Hospital, which is a tertiary care hospital in Mumbai, India. A retrospective strategy was used for data collection. The study used the data of patients with the symptoms of COVID-19 referred to our centre during May 2020. Symptomatic patients were those having at least 3 out of 4 symptoms (fever, dry cough, shortness of breath, and myalgia). Our study also included COVID-19 negative individuals, namely people having COVID-19related symptoms but negative results according to realtime reverse transcriptase polymerase chain reaction (RT-PCR) test, as controls. The patients were diagnosed with COVID-19 based on the results of RT-PCR. ${ }^{4}$ Data of patients with incomplete demographic information and incomplete test results were excluded from the analysis. Biochemical parameters were compared between negative COVID-19 and positive COVID-19 patients.

\section{Data Collection}

Hospital records were searched to identify patients with and without COVID-19 disease admitted with COVID19-related symptoms. Finally, the data of 166 patients was used for analysis. Information about age, gender, and values of biochemical parameters were noted and used for data analysis. As the study was retrospective, we could get information neither about previous medical history nor about the severity of infection in the patients.

\section{Biochemical Parameters}

The values of biochemical parameters of COVID-19 patients were collected from Central Clinical Biochemistry Laboratory of Seth G S Medical College and KEM Hospital, Mumbai. Biochemical parameters included liver functional tests (serum alanine aminotransferase [ALT], aspartate aminotransferase [AST], total protein, albumin, bilirubin total, and bilirubin direct) and renal function tests (serum BUN, creatinine, sodium, potassium, and chloride). The tests had been conducted on a fully automatic Clinical Biochemistry analyser- AU680 (ERBA Diagnostics, Mannheim). All the tests were performed using ERBA diagnostic reagents manufactured by Transasia Bio-Medicals LTD, Solan, Himachal Pradesh, India.

\section{Statistical Analysis}

GraphPad Prism software was used for statistical analysis. Quantitative variables were presented as mean and standard deviation (SD), as they were normally distributed. Normality was checked using KolmogorovSmirnov test. Group-wise comparison of various biochemical parameters was done using unpaired $t$ test. Categorical variables were displayed with percentage, and between groups comparisons were performed using chi-square test. The ROC curve was generated for the biochemical parameters, which showed significant differences between the groups. The area under the ROC curve (AUC) was determined to check the optimal cut-off to evaluate the predictive performance of these parameters for COVID-19. An AUC value of 0.9-1.0 signified as a "perfect biomarker with excellent accuracy", 0.8-0.9 as "very good", 0.6-0.7 as "sufficient", and a value of 0.5 or lower was signified as "no better than what would be expected by chance". The optimal cut-off value was the value that had the highest combined sensitivity and specificity. $P$ value of $<0.05$ was considered as statistically significant.

\section{Results}

The study subjects $(\mathrm{n}=166)$ were divided into 2 groups: patients with COVID-19-related symptoms but negative for RT-PCR (group 1, $\mathrm{n}=67$ ) and RT-PCR positive COVID-19 patients (group 2, $\mathrm{n}=99$ ).

Table 1 presents the comparison of demographic characteristics between the groups. In the nonCOVID-19 group, $61.2 \%$ were male while in the positive COVID-19 group, $74.4 \%$ were male. The patients in the COVID-19 positive group had a significantly older age than the control group (non-COVID group) $(P<0.0002)$. 
Table 1. Baseline Demographic Characteristics of Study Population

\begin{tabular}{lccc}
\hline Characteristics & $\begin{array}{c}\text { COVID-19 } \\
\text { Negative } \\
(\mathbf{n = 6 7 )}\end{array}$ & $\begin{array}{c}\text { COVID-19 } \\
\text { Positive } \\
(\mathbf{n}=99)\end{array}$ & $\boldsymbol{P}$ Value \\
\hline Gender Males, No. $(\%)$ & $41(61.2)$ & $74(74.4)$ & $>0.08$ \\
Age $(y)($ Mean \pm SD) & $40.08 \pm 15.8$ & $49.29 \pm 14.4$ & 0.0002 \\
Range & $(7-78$ years $)$ & $(23-86$ years $)$ & \\
Confidence interval & $36.1-43.9$ & $46.4-52.1$ & \\
\hline
\end{tabular}

No significant difference was observed with regards to gender between the groups.

Table 2 depicts the comparisons of organ functional tests between COVID-19 negative and COVID-19 positive patients. COVID-19 positive patients had significantly higher serum AST $(P=0.05)$, ALT $(P=0.0006)$, and direct bilirubin $(P=0.005)$ levels while serum total protein (TP), albumin, and total bilirubin showed no significant difference $(P>0.05)$.

Results of kidney functional tests showed that the mean values of BUN and serum creatinine were significantly raised in COVID-19 positive group $(P<0.001$ for both parameters) compared to COVID-19 negative group. No significant difference was observed in the levels of serum electrolytes $\left(\mathrm{Na}^{+}, \mathrm{K}^{+} \& \mathrm{Cl}^{-}\right)$between the groups $(P>0.05)$.

ROC curve analysis was conducted for serum AST,

Table 2. Comparison of Biochemical Parameters in Study Population

\begin{tabular}{|c|c|c|c|c|c|}
\hline \multirow[b]{2}{*}{ Characteristics } & \multicolumn{2}{|c|}{ COVID-19 Negative } & \multicolumn{2}{|c|}{ COVID-19 Positive } & \multirow[b]{2}{*}{$P$ Value } \\
\hline & $\begin{array}{c}\text { (Mean } \pm \text { SD) } \\
95 \% \mathrm{Cl}\end{array}$ & $N$ & $\begin{array}{c}(\text { Mean } \pm \text { SD) } \\
95 \% \mathrm{Cl}\end{array}$ & $N$ & \\
\hline \multicolumn{6}{|c|}{ Liver Function Test Parameters } \\
\hline $\begin{array}{l}\text { Serum AST } \\
\text { (IU/L) }\end{array}$ & $\begin{array}{c}26.21 \pm 6.45 \\
(24.6-27.7)\end{array}$ & 67 & $\begin{array}{c}106.4 \pm 294.50 \\
(45.8-167.1)\end{array}$ & 93 & $<0.05$ \\
\hline $\begin{array}{l}\text { Serum ALT } \\
\text { (IU/L) }\end{array}$ & $\begin{array}{c}16.10 \pm 8.15 \\
(14.1-18.1)\end{array}$ & 67 & $\begin{array}{c}96.97 \pm 187.90 \\
(58.2-135.7)\end{array}$ & 93 & $<0.0006$ \\
\hline $\begin{array}{l}\text { Serum total } \\
\text { protein }(\mathrm{g} / \mathrm{dL})\end{array}$ & $\begin{array}{c}6.25 \pm 0.79 \\
(6.0-6.4)\end{array}$ & 67 & $\begin{array}{c}6.31 \pm 0.82 \\
(6.1-6.5)\end{array}$ & 90 & 0.685 \\
\hline $\begin{array}{l}\text { Serum albumin } \\
(\mathrm{g} / \mathrm{dL})\end{array}$ & $\begin{array}{c}3.16 \pm 0.46 \\
(3.0-3.3)\end{array}$ & 67 & $\begin{array}{c}5.01 \pm 12.44 \\
(2.4-7.6)\end{array}$ & 90 & 0.228 \\
\hline $\begin{array}{l}\text { Serum bilirubin } \\
\text { total }(\mathrm{mg} / \mathrm{dl})\end{array}$ & $\begin{array}{c}1.13 \pm 0.35 \\
(0.9-1.2)\end{array}$ & 25 & $\begin{array}{c}8.0 \pm 22.97 \\
(0.4-15.5)\end{array}$ & 38 & $<0.15$ \\
\hline $\begin{array}{l}\text { Serum bilirubin } \\
\text { direct }(\mathrm{mg} / \mathrm{dl})\end{array}$ & $\begin{array}{c}0.32 \pm 0.10 \\
(0.2-0.3)\end{array}$ & 25 & $\begin{array}{c}2.90 \pm 4.32 \\
(1.4-4.3)\end{array}$ & 38 & $<0.005$ \\
\hline \multicolumn{6}{|c|}{ Kidney Function Test Parameters } \\
\hline $\mathrm{BUN}(\mathrm{mg} / \mathrm{dl})$ & $\begin{array}{c}9.76 \pm 5.86 \\
(8.3-11.1)\end{array}$ & 67 & $\begin{array}{c}27.7 \pm 22.14 \\
(23.3-32.1)\end{array}$ & 99 & $<0.0001$ \\
\hline $\begin{array}{l}\text { Serum } \\
\text { creatinine (mg/ } \\
\text { dl) }\end{array}$ & $\begin{array}{c}0.17 \pm 0.02 \\
(0.9-1.0)\end{array}$ & 67 & $\begin{array}{c}1.93 \pm 1.71 \\
(1.5-2.2)\end{array}$ & 99 & $<0.0001$ \\
\hline $\begin{array}{l}\text { Serum sodium } \\
(\mathrm{mmol} / \mathrm{L})\end{array}$ & $\begin{array}{l}136.3 \pm 4.05 \\
(135.3-135.7)\end{array}$ & 66 & $\begin{array}{l}135.4 \pm 8.57 \\
(133.7-137.2)\end{array}$ & 97 & 0.44 \\
\hline $\begin{array}{l}\text { Serum K } \\
(\mathrm{mmol} / \mathrm{L})\end{array}$ & $\begin{array}{c}3.70 \pm 0.44 \\
(3.5-3.8)\end{array}$ & 66 & $\begin{array}{c}3.83 \pm 0.70 \\
(3.6-3.9)\end{array}$ & 97 & 0.19 \\
\hline $\begin{array}{l}\text { Serum chloride } \\
(\mathrm{mmol} / \mathrm{L})\end{array}$ & $\begin{array}{c}103 \pm 4.01 \\
(102.0-104.0)\end{array}$ & 66 & $\begin{array}{c}101.3 \pm 7.90 \\
(99.6-102.9)\end{array}$ & 97 & 0.10 \\
\hline
\end{tabular}

Abbreviations: $\mathrm{Cl}$ : Confidence interval, BUN, blood urea nitrogen creatinine ALT, alanine aminotransferase; AST, aspartate aminotransferase.
ALT, BUN, and serum creatinine. Table 3, Figure 1, and Figure 2 illustrate the ROC analysis of the abovementioned parameters for predicting COVID-19 positivity. AST (AUC- 0.826), ALT (AUC- 0.8525), and BUN (AUC- 0.8097) showed very good accuracy, and serum creatinine (AUC- 0.7971) showed good accuracy in predicting COVID-19 positive PCR results. The best predictive performance was achieved with serum ALT. The optimum cut-off value for ALT was $36.0 \mathrm{IU} / \mathrm{L}$ (sensitivity of $46.3 \%$ and specificity of $100 \%$ ). The cutoff values along with sensitivity and specificity values of other studied parameters have been presented in Table 3.

\section{Discussion}

It is well-known that the COVID-19 disease is absolutely new to the world, and there is an urgent need to discover biochemical markers for diagnosis, prognosis, and assessment of the disease severity. However, the establishment of a new biomarker is a time-consuming process. Serum biochemical parameters are commonly used, easy to measure, routine, and relatively cheap and can help in diagnosis and determining the prognosis of COVID-19 disease. ${ }^{6}$ Since COVID-19 is spreading very rapidly, we need to find how these basic parameters can be used optimally in combination with artificial intelligence and other gold standard tests such as computed tomography (CT) results and RT-PCR for establishing the diagnosis and determining the prognosis of COVID-19 disease.

The present study was designed to check the feasibility of using routine biochemical markers for identifying COVID-19 positive patients in an Indian population.

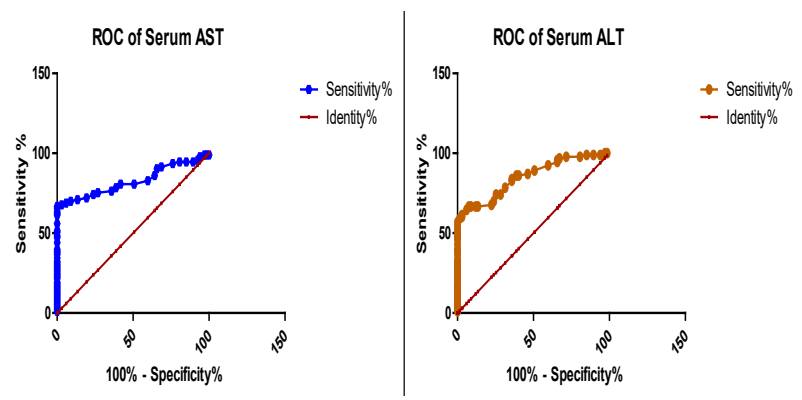

Figure 1. Receiver Operating Characteristic (ROC) Analysis of Serum AST and ALT for the Prediction of COVID-19.

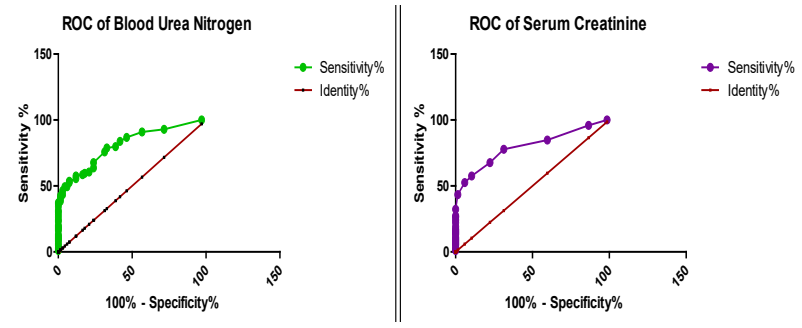

Figure 2. Receiver Operating Characteristic (ROC) Analysis of BUN and Serum Creatinine for the Prediction of COVID-19. 
Table 3. ROC Analysis of Serum Transaminases, BUN and Serum Creatinine for the Prediction of COVID-19

\begin{tabular}{|c|c|c|c|c|c|c|c|c|}
\hline Parameters & Cut off & AUC & $95 \% \mathrm{Cl}$ & Sensitivity & Specificity & $\begin{array}{c}\text { Positive Predictive } \\
\text { Value }(\%)\end{array}$ & $\begin{array}{c}\text { Negative Predictive } \\
\text { Value }(\%)\end{array}$ & $P$ Value \\
\hline Serum AST (IU/L) & 38.0 & 0.826 & 0.76 to 0.89 & $66.6 \%$ & $100 \%$ & 100 & 68.3 & 0.0001 \\
\hline Serum ALT (IU/L) & 36.0 & 0.8525 & 0.79 to 0.90 & $56.9 \%$ & $100 \%$ & 100 & 62.6 & 0.0001 \\
\hline $\mathrm{BUN}(\mathrm{mg} / \mathrm{dL})$ & 27.5 & 0.8097 & 0.74 to 0.87 & $38.4 \%$ & $98.5 \%$ & 97.4 & $51.9 \%$ & 0.0001 \\
\hline Serum creatinine $(\mathrm{mg} / \mathrm{dL})$ & 1.45 & 0.7971 & 0.73 to 0.86 & $43.4 \%$ & $98.5 \%$ & 97.7 & 54.1 & 0.0001 \\
\hline
\end{tabular}

Abbreviations: $\mathrm{Cl}$ : Confidence interval, BUN, blood urea nitrogen creatinine; ALT, alanine aminotransferase; AST, aspartate aminotransferase.

In our study, it was observed that the mean age (49.29; $\mathrm{SD}=14.4$ years) of COVID-19 positive group was higher compared to the control group (40.08; $\mathrm{SD}=15.8$ ), indicating that age is significantly associated with the COVID-19 disease.

In the present study, $52.5 \%(n=52 / 99)$ of the COVID-19 positive patients had abnormal BUN levels (cut-off $=20$ $\mathrm{mg} / \mathrm{dL})$, and $57.5 \%(\mathrm{n}=57 / 99)$ had abnormal creatinine levels, indicating renal dysfunction. Overall, $68.8 \%$ ( $n=64 / 93$ ) of the COVID-19 positive patients had abnormal levels of serum AST (cut-off $=35$ IU/L), and $50.5 \%(n=47 / 93)$ had abnormal levels of serum ALT, indicating liver dysfunction.

Although we did not have any information regarding preexisting comorbidities in the patients, our data indicated that the novel coronavirus has pathophysiological impacts on various vital organs including the liver and kidney. Multiorgan impacts of the coronavirus may be due to expression of angiotensin converting enzyme 2 receptors on hepatocytes and renal cells, the cytokine storm, decreased supply of oxygen to these organs, endotheliitis, and thromboembolic conditions, which have been observed in COVID-19 patients. $^{7}$

Although this virus mainly attacks respiratory system, evidence that the infection can also harm other organs such as kidneys, the heart, intestine, and liver have been found by various studies, which can play significant role in the disease progression and mortality. ${ }^{8}$ In our study, we compared kidney and liver functional parameters between COVID-19 and non-COVID-19 patients and observed that BUN, serum creatinine, ALT, and AST were significantly higher in the COVID-19 positive group. These results provide evidence that this disease affects kidney and liver function.

Furthermore, ROC curve analysis was performed to determine the specificity and sensitivity of these tests for the diagnosis of COVID-19 in suspected cases. AUCs of AST, ALT, and BUN were higher than $0.80 \%$, suggesting that these parameters are very good predictors of the disease and can be used for the diagnosis of COVID-19 in suspected cases.

Mardani et al in 2020 conducted a similar study in Iran to assess the accuracy of biochemical parameters to predict RT-PCR positivity in COVID-19 cases and observed that RT-PCR positive patients had significantly elevated serum AST, ALT, and Urea levels. They also calculated the AUCs of various laboratory parameters and observed that ALT $(\mathrm{AUC}=0.879)$ and urea $(\mathrm{AUC}=0.835)$ showed very good accuracy in predicting RT-PCR positive COVID-19 cases. $^{9}$

Another study was conducted by Guan et al in which the data of 1099 laboratory-confirmed COVID-19 patients was extracted and compared between severe and non-severe patients. They observed elevated levels of AST in 112 (18.2\%) of 615 non-severe patients and 56 (39.4\%) of 142 severe patients. Raised serum ALT levels were observed in 120 (19.8\%) of 135 patients with nonsevere disease and 38 (28.1\%) of 135 severe patients. Elevated values of creatinine were found in $6(1 \%)$ of 614 non-severe patients and $6(4.3 \%)$ of 138 severe patients. Moreover, serum levels of ALT, AST, and creatinine were significantly higher $(P<0.043, P<0.001$, and $P<0.012$, respectively) in the severe group than non-severe group. ${ }^{10}$ As swift diagnosis and isolation of patients is vital to halt the spread of COVID-19 and start early treatment in severe cases to prevent mortality, routine biochemical tests can be useful to diagnose the disease and early detect severe COVID-19 cases and symptomatic patients with false negative RT-PCR results.

\section{Limitations of the Study}

Since this was a retrospective study, we could not collect the information regarding previous history, comorbidities of patients, and the severity of COVID-19. Furthermore, there may be some bias due to the difference in the age of COVID-19 negative and positive patients. Further studies on COVID-19 negative and positive patients with similar age spectrum are suggested.

\section{Conclusion}

Our results suggest that serum ALT, AST, creatinine, and BUN can be used as useful parameters for predicting COVID-19 positivity, early diagnosis of positive cases, and those who may develop severe symptoms.

\section{Ethical Approval}

The Ethics Committee of Seth G S Medical College \& KEM Hospital, Mumbai approved the study protocol (Code No- EC/OA-117/2020). 


\section{Conflict of Interest Disclosure}

Authors declare no conflict of interest.

\section{Funding/Support}

Not applicable.

\section{Authors' Contribution}

$\mathrm{MB}, \mathrm{SM}, \mathrm{AC}$, and SK conceived and designed the study. SM, MB, and SK collected data. SM analyzed the data and wrote the paper. AC revised and edited the paper. All authors read and approved the final manuscript.

\section{References}

1. Q\&A on coronaviruses (COVID-19). World Health Organization web site. https://www.who.int/news-room/ q-a-detail/q-a-coronaviruses. Updated April 17, 2020. Accessed May 12, 2020.

2. COVID-19 Pandemic in India. Wikipedia website. the free encyclopedia Web site. https://en.wikipedia.org/ wiki/2020_coronavirus_pandemic_in_India. Updated June 23, 2020. Accessed May 12, 2020.

3. Karla K, Shashidhar KN, Nallagangula KS. Diagnostic strategies for COVID-19. Acta Sci Med Sci. 2020;4(5):1821.
4. Xiang J, Wen J, Yuan X, et al. Potential biochemical markers to identify severe cases among COVID-19 patients. medRxiv. 2020. doi:10.1101/2020.03.19.20034447

5. Huang C, Wang Y, Li X, et al. Clinical features of patients infected with 2019 novel coronavirus in Wuhan, China. Lancet. 2020;395(10223):497-506. doi:10.1016/s01406736(20)30183-5

6. Singhal T. A review of coronavirus disease-2019 (COVID-19). Indian J Pediatr. 2020;87(4):281-286. doi:10.1007/s12098-020-03263-6

7. Zaim S, Chong JH, Sankaranarayanan V, Harky A. COVID-19 and multiorgan response. Curr Probl Cardiol. 2020;45(8):100618. doi:10.1016/j.cpcardiol.2020.100618

8. Basilio P. COVID-19: Damage Found in Multiple Organ Systems. MDLinx website. https://www.mdlinx.com/ article/covid-19-damage-found-in-multiple-organ-syste ms/7aEtHY8SPWz1Nutsg7nhrf. Updated April 16, 2020. Accessed May 17, 2020.

9. Mardani R, Ahmadi Vasmehjani A, Zali F, et al. Laboratory parameters in detection of COVID-19 patients with positive RT-PCR; a diagnostic accuracy study. Arch Acad Emerg Med. 2020;8(1):e43.

10. Guan WJ, Ni ZY, Hu Y, et al. Clinical characteristics of coronavirus disease 2019 in China. N Engl J Med. 2020;382(18):1708-1720. doi:10.1056/NEJMoa2002032 